\title{
Interannual surface velocity variations of Pine Island Glacier, West Antarctica
}

\author{
Bernhard T. RABUS, ${ }^{*}$ Oliver LANG \\ German Remote Sensing Center (DFD), Oberpfaffenhofen, D-82234 Wessling, Germany \\ E-mail:brabus@mda.ca
}

\begin{abstract}
The surface velocity of Pine Island Glacier, West Antarctica, during the period 1992-2000 is measured with synthetic aperture radar feature-tracking techniques. Over the observation period, we find a monotonic acceleration with a spatially uniform amplitude of about $12 \%$ of the surface velocity. The acceleration extends $>80 \mathrm{~km}$ inland of the grounding line into a zone of prominent arcuate crevasses. The upper limit of these crevasses has migrated up-glacier by $0.2 \mathrm{~km} \mathrm{a}^{-1}$ correlated with a velocity increase of similar size in the crevassed zone. On the other hand, there is no clear correlation between the velocity variations and observations of grounding-line migration. These findings suggest ongoing dynamic thinning of Pine Island Glacier, providing independent confirmation of recent interferometric results obtained by Rignot and others (2002).
\end{abstract}

\section{INTRODUGTION}

Several theoretical studies have identified the Amundsen Sea sector of the West Antarctic ice sheet (WAIS) as inherently unstable with respect to changes in sea level and climate (Hughes, 1973; Fastook, 1984). Others consider such instability unlikely (e.g. Bentley, 1998). It is difficult to settle this controversy from direct observations in the region on the large ice streams of Pine Island Glacier (PIG) and Thwaites Glacier (TG). Recent changes have been observed for PIG, but these may have many causes other than icesheet instability (Vaughan and others, 2001). Nevertheless, the long-term monitoring of unstable ice flow should eventually provide the data necessary to uncover the different forcings behind the observed flow changes. Indirectly, this then leads back to the question of ice-sheet instability.

Analyzing unstable ice flow requires (i) measurements of ice thickness and basal conditions, and (ii) long-term observations of ice velocity and surface topography. Changes of velocity and surface topography provide direct evidence of unstable flow. Knowledge of geometry and basal boundary conditions of the ice mass are necessary to quantify the flow change as well as to constrain internal and external forcings (e.g. through changes of longitudinal or basal shear stress).

Ice-thickness data for PIG are summarized in Vaughan and others (2001). The data mainly consist of three pulseradar profiles that are approximately aligned with the ice flow on the lower portion of PIG (Corr and others, 2001). The profiles show a pronounced inland slope of basal topography to $>1300 \mathrm{~m}$ below sea level, with a corresponding increase of ice thickness to a maximum of $2500 \mathrm{~m}$. Between

\footnotetext{
* Present address: MacDonald Dettwiler, 138000 Commerce Parkway, Richmond, British ColumbiaV6V 2J3, Canada.
}

the grounding line and about $20 \mathrm{~km}$ inland the glacier forms a marginally grounded ice plain (Corr and others, 2001). A comprehensive measurement of the basal topography of the PIG catchment by airborne pulse radar or seismic sounding will have to await a future field program.

In contrast, the acquisition of representative long-term time series of surface topography and ice velocity has been possible with space-borne remote-sensing techniques. European Remote-sensing Satellite (ERS) radar altimetry was used to measure surface topography (Bamber and Bindschadler, 1997) and its temporal change (Wingham and others, 1998). Results over the period 1992-96 showed an overall drop in surface elevation of about $0.1 \mathrm{~m} \mathrm{a}^{-1}$ for the combined drainage basins of PIG and TG. For 1992-99, Shepherd and others (2001) carried out a similar but spatially more detailed study for the lower (grounded) part of PIG. Here the drop in surface elevation gradually increased down-glacier to more than $-1.5 \mathrm{~m} \mathrm{a}^{-1}$ just above the grounding line. Data from Landsat and synthetic aperture radar (SAR) sensors were used to measure the surface velocity of PIG with featuretracking (Scambos and others, 1992; Rosanova and others, 1998) as well as interferometric methods (Rignot 1998; Stenoien and Bentley, 2000). A problem is the lack of comparability of the velocity data produced by these earlier studies. Reasons are the differing sensor viewing geometries and coordinate reference systems that often cast doubt on whether changes observed between the studies are real or merely artifacts of interpolation. A notable exception is a homogeneous time series of interferometric velocity measurements on PIG recently published by Rignot and others (2002). SAR interferometric methods have also been used to deduce a $3.5 \mathrm{~km}$ retreat of the grounding line of PIG between 1992 and 1994 (Rignot, 1998).

In this paper, we present a simple technique for measuring ice velocity using feature tracking of ERS data along longitudinal profiles. With this technique we are able to produce reliable time series of seasonal as well as (decadal- 


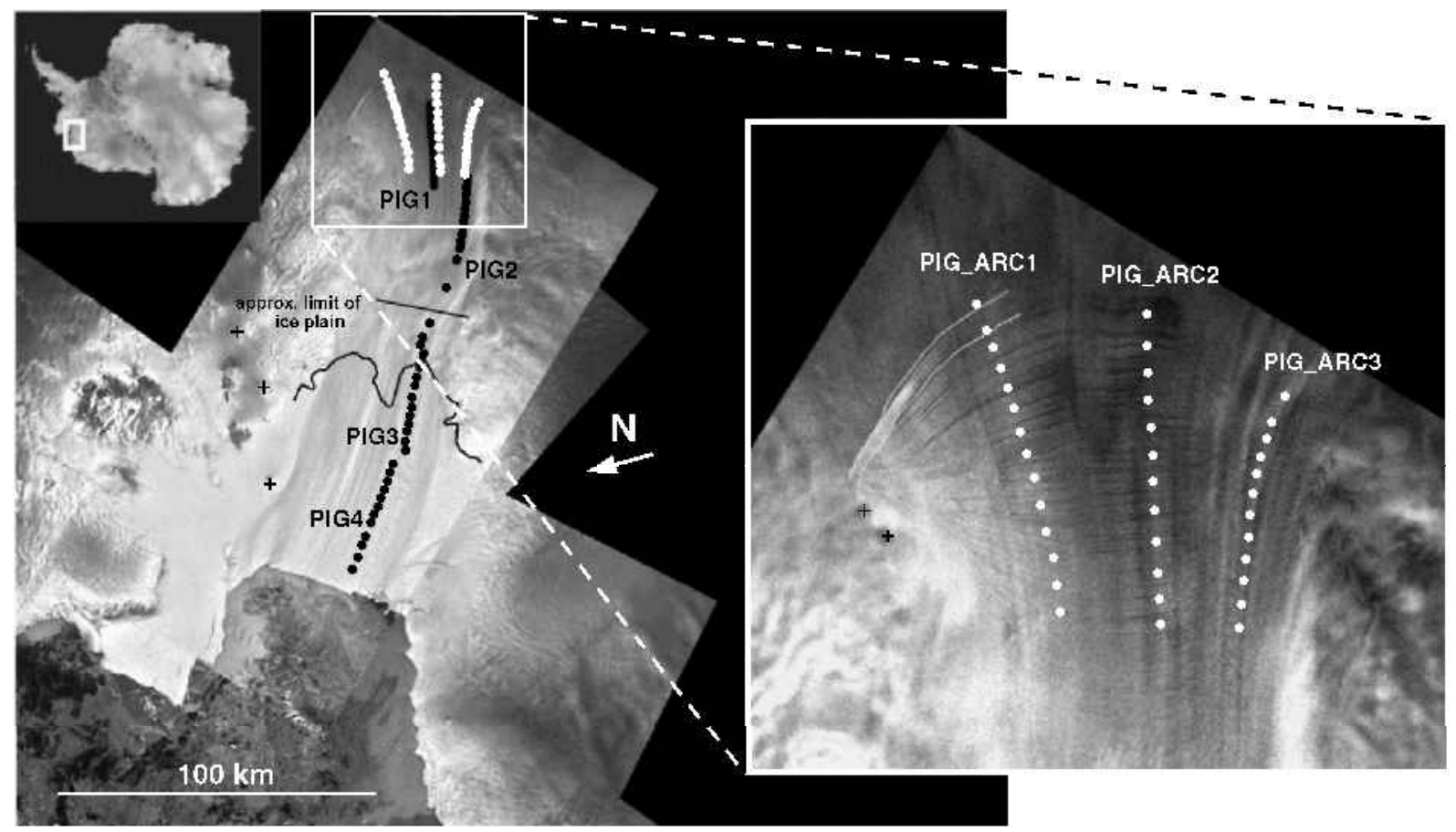

Fig. 1. Location map. ERS SAR backscatter mosaic of lower PIG and blow-up of the "arcuate crevasse region". Feature-tracking profiles are shown as dots, each dot representing an individual measurement location. Black lines delineate the grounding-line position. White lines in the blow-up delineate the onset of the arcuate crevasse zone in 1994 and 2000 (the up-glacier line corresponds to the later date).

scale) interannual velocity variations for coastal ice streams. Consistent extension of these time series with future SAR data from ERS and ENVISAT will be straightforward. The technique is applied to PIG using the longitudinal profiles shown in Figure 1. Results are compared to those of the complementary interferometric analysis by Rignot and others (2002). A corresponding analysis of TG with the feature-tracking technique is provided in the companion paper (Rabus and others, 2003).

\section{METHODS}

We use feature tracking on SAR amplitude pairs to measure ice velocities. Further we use repeat mapping in individual SAR amplitudes and differential SAR interferograms to monitor the position of the uppermost arcuate crevasse and the grounding line, respectively. Both methods, feature tracking and repeat mapping, generally require accurate geo-registration of SAR images. This includes careful estimation of errors due to insufficient knowledge of terrain elevation that bias the measured velocities or position changes. Consequently, we describe the relevant details of geo-registration first.

\section{Geocoded SAR data}

The geocoded ERS SAR amplitude product (geocoded ellipsoid corrected (GEC)) provided by the European Space Agency was used exclusively for all feature-tracking velocity measurements as well as for measuring the temporal evolution of the up-glacier boundary of the zone of arcuate crevasses. The physical resolution of the GECs is better than $20 \mathrm{~m}$; their pixel spacing is $12.5 \mathrm{~m}$. During the processing of the GEC, the corresponding SAR amplitude is projected to Universal Polar Stereographic (UPS) coordinates using precise orbit information with an accuracy of $<0.2 \mathrm{~m}$. The pro- jection uses a constant reference elevation $h_{0}$ on the World Geodetic System 1984 (WGS84) ellipsoid. We used GEGs processed to $h_{0}=0 \mathrm{~m}$ for the longitudinal velocity profiles PIG1-PIG4 (Fig. 1). These profiles span an elevation range from sea level to about $700 \mathrm{~m}$. For a detailed velocity study of the arcuate crevasse zone (profiles PIG_ARCl-PIG_ARC3 in Fig. 1) we used another set of GECs with $h_{0}=700 \mathrm{~m}$ that corresponds to the mean elevation of this region (Bamber and Bindschadler, 1997).

A deviation $\Delta h=h-h_{0}$ of true terrain elevation $h$ with respect to $h_{0}$ shifts the horizontal coordinates of a corresponding pixel by $\Delta x_{\mathrm{r}}=\Delta h(\sin \theta)^{-1}$ in look direction, with $\theta$ being the satellite look angle. For ERS with $\theta \approx 23.5^{\circ}$ we have $\Delta x_{\mathrm{r}} \approx 2.5 \Delta h$. In flight direction there is a further shift $\Delta x_{\mathrm{t}}$, which arises during SAR focusing from the dependence of the Earth rotational velocity on terrain elevation (Schreier, 1993). At $75^{\circ}$ latitude we get $\Delta x_{\mathrm{t}} \approx 0.04 \Delta h$, which is two orders of magnitude smaller than the shift in look direction. For a feature-tracking image pair not acquired from two identical sensor positions, the shifts $\Delta x_{\mathrm{r}}$ of the two images will not precisely cancel. This will cause a systematic topographic error of horizontal velocity in look direction,

$$
\varepsilon(\Delta h)=\frac{B_{\perp}}{\Delta t r \sin ^{2} \theta} \Delta h .
$$

Here, $r$ is the range distance, and $\theta$ is the look angle; $B_{\perp}$ and $\Delta t$ are the spatial (look-perpendicular) and temporal baseline of the feature-tracking pair, respectively. Table 1 shows the expected systematic velocity errors due to geo-registration for all feature-tracking pairs used in this study. Conservatively, we have estimated $\Delta h=1000 \mathrm{~m}$ and $\Delta h= \pm 100 \mathrm{~m}$ for pairs with $h_{0}=0 \mathrm{~m}$ and $h_{0}=700 \mathrm{~m}$, respectively. The results show that with the exception of one pair (row four in Table 1) with a short 105 day temporal baseline, the topographic velocity error is always considerably smaller than 
Table 1. Velocity biases due to terrain elevation differences $\Delta z$ with respect to GEC reference elevation $z_{\mathrm{ref}}$ (Equation (1)). Flight direction is ascending in all cases

\begin{tabular}{|c|c|c|c|c|c|c|c|}
\hline FM pair & Orbit 1 & Orbit 2 & Track 1 & Track 2 & $\begin{array}{c}B_{\perp} \\
\mathrm{m}\end{array}$ & $\begin{array}{c}\Delta t \\
\text { days }\end{array}$ & $\begin{array}{c}\text { Max. velocity bias } \\
\mathrm{m} \mathrm{a}^{-1}\end{array}$ \\
\hline
\end{tabular}

Profiles PIG1,2,3: frames $5589+5607, z_{\text {ref }}=0 \mathrm{~m} \rightarrow \Delta z \in[0,1000] \mathrm{m}$

\begin{abstract}
12 Nov. 1995 - 25 Feb. 1996 12 Nov. 1995 - 28 Oct.1996 25 Feb. 1996 - 28 Oct. 1996 28 Oct. 1996 - 10 Feb. 1997 25 Feb. 1996 - 10 Feb. 1997 15 Feb. 1999 - 31 Jan. 2000 31 Jan. 2000 - 2 Oct. 2000
\end{abstract}

9 Feb. 1992 - 12 Apr. 1992

12 Apr. 1992 - 15 Mar. 1994

15 Mar. 1994 - 12 Nov. 1995

15 Mar. 1994 - 25 Feb. 1996

25 Feb. 1996 - 10 Feb. 1997

10 Feb. 1997 - 15 Feb. 1999

15 Feb. 1999 - 31 Jan. 2000

31 Jan. 2000 - 2 Oct. 2000

$\begin{array}{cc}\text { E1-22625 } & \text { E1-24128 } \\ \text { E1-22625 } & \text { E2-07962 } \\ \text { E1-24128 } & \text { E2-07962 } \\ \text { E2-07962 } & \text { E2-09465 } \\ \text { E1-24128 } & \text { E2-09465 } \\ \text { E2-19986 } & \text { E2-24996 } \\ \text { E2-24996 } & \text { E2-28503 }\end{array}$

92

92

92

92

92

92

92

92
92
92
92
92
92
92

35
26
-9
947
938
442
81

105
351
246
105
351
350
245

Profiles PIG_ARC1,2,3: frame 5589, $z_{\mathrm{ref}}=700 \mathrm{~m} \rightarrow \Delta z \in[-100,100] \mathrm{m}$

$\begin{array}{lcccccc}\text { E1-02970 } & \text { E1-07251 } & 35 & 92 & 5169 & 300 & 4.7 \\ \text { E1-07251 } & \text { E1-13923 } & 92 & 35 & 5295 & 465 & 3.1 \\ \text { E1-13923 } & \text { E1-22625 } & 35 & 92 & 4835 & 607 & 2.2 \\ \text { E1-13923 } & \text { E1-24128 } & 35 & 92 & 4865 & 412 & 3.2 \\ \text { E1-24128 } & \text { E2-09465 } & 92 & 92 & 938 & 351 & 0.7 \\ \text { E2-09465 } & \text { E2-19986 } & 92 & 92 & -993 & 735 & 0.4 \\ \text { E2-19986 } & \text { E2-24996 } & 92 & 92 & 442 & 350 & 0.3 \\ \text { E2-24996 } & \text { E2-28503 } & 92 & 92 & 81 & 245 & 0.1\end{array}$

the $25 \mathrm{~m} \mathrm{a}^{-1}$ random error that is estimated for the featuretracking method later on.

Equation (1) equally applies to the repeat mapping of features in individual images as long as only changes with respect to a "master" scene are considered. For mapping the upper limit of the arcuate crevasse zone, we solely used GEGs with $h_{0}=700 \mathrm{~m}$ (lower half of Table 1). Errors due to geo-registration are an order of magnitude smaller than the $100 \mathrm{~m}$ accuracy estimated for these measurements later on. For the detection of grounding-line position, we used complex ERS SAR data (single look complex (SLC)) from the tandem and ice phase. Acquisition time, orbit and frame

Table 2. SLCs grouped according to differential interferograms used for the repeat mapping of the grounding line

\begin{tabular}{|c|c|c|c|c|}
\hline Date of $S L C$ & Orbit & Track & Flight dir. & $\begin{array}{c}B_{\perp} \\
\mathrm{m}\end{array}$ \\
\hline $\begin{array}{l}29 \text { Feb. } 1992 \\
6 \text { Mar. } 1992 \\
12 \text { Mar. } 1992\end{array}$ & $\begin{array}{c}\text { E1-02970 } \\
\text { E1-03056 } \\
\text { E1-03142 }\end{array}$ & $\begin{array}{l}24 \\
24 \\
24\end{array}$ & Desc. & $\begin{array}{c}74 \\
155\end{array}$ \\
\hline $\begin{array}{l}8 \text { Mar. } 1994 \\
11 \text { Mar. } 1994 \\
14 \text { Mar. } 1994\end{array}$ & $\begin{array}{l}\text { E1-03260 } \\
\text { E1-03346 } \\
\text { E1-03432 }\end{array}$ & $\begin{array}{l}24 \\
24 \\
24\end{array}$ & Desc. & $\begin{array}{l}70 \\
16\end{array}$ \\
\hline $\begin{array}{l}11 \text { Nov. } 1995 \\
12 \text { Nov. } 1995 \\
\text { 20 Jan. } 1996 \\
\text { 21 Jan. } 1996\end{array}$ & $\begin{array}{c}\text { E1-22614 } \\
\text { E2-02941 } \\
\text { E1-23616 } \\
\text { E2-03943 }\end{array}$ & $\begin{array}{l}81 \\
81 \\
81 \\
81\end{array}$ & Desc. & $\begin{array}{l}110 \\
227\end{array}$ \\
\hline $\begin{array}{l}\text { 21 Jan. } 1996 \\
\text { 22 Jan. } 1996 \\
\text { 25 Feb. } 1996 \\
\text { 26 Feb. } 1996\end{array}$ & $\begin{array}{c}\text { E1-23627 } \\
\text { E2-03954 } \\
\text { E1-24128 } \\
\text { E2-04455 }\end{array}$ & $\begin{array}{l}92 \\
92 \\
92 \\
92\end{array}$ & Asc. & $\begin{array}{r}-270 \\
136\end{array}$ \\
\hline $\begin{array}{l}29 \text { Feb. } 2000 \\
1 \text { Mar. } 2000 \\
4 \text { Mar. } 2000 \\
5 \text { Mar. } 2000\end{array}$ & $\begin{array}{c}\text { E1-45102 } \\
\text { E2-25429 } \\
\text { E1-45102 } \\
\text { E2-25486 }\end{array}$ & $\begin{array}{l}24 \\
24 \\
81 \\
81\end{array}$ & Desc. & $\begin{array}{l}-69 \\
-17\end{array}$ \\
\hline
\end{tabular}

of the SLC data are listed in Table 2. SLGs between solid lines were used to form differential interferograms. In a later step, these differential interferograms were geocoded to $h_{0}=0 \mathrm{~m}$. Table 2 shows that grounding-line location is mapped in differential interferograms of different frame and track. Nevertheless, topography-dependent biases of Equation (1) are negligible here at the $400 \mathrm{~m}$ accuracy claimed for these measurements later on. This is because deviations of ice surface elevation from $h_{0}=0 \mathrm{~m}$ are typically $<100 \mathrm{~m}$ for the grounding zone.

No tie points are used in GEC production. This allows us to check the validity of the presented error analysis using feature tracking and repeat mapping checks on the nunataks and ice rises shown in Figure $1(+$ symbols $)$. For all GEC pairs analyzed (lower part of Table $1 ; h_{0}=700 \mathrm{~m}$ ), these points come out stationary to better than half a pixel $(6.25 \mathrm{~m})$ per year, in accordance with the expected errors listed in Table 1 . At the same time, this result provides overall validation for our implementation of the feature-tracking technique. The technique is described in the following.

\section{Feature-tracking velocity measurements}

To obtain velocity averages that are relevant on seasonal and interannual time-scales, we track surface features such as crevasses that are passively advected with glacier flow. We use a straightforward implementation of the feature-tracking method similar to that of Scambos and others (1992). We input two GECs of the same scene with a temporal baseline of months or years. To measure the surface motion at a specified location, we cut out and normalize a surrounding square chip of side length $1.5 \mathrm{~km}$ in the first image. Within a specified search depth we shift the second amplitude image on a two-dimensional grid with search dimension $D$ and search step $d$. For each individual shift we create another normalized chip from the second image. As a correlation measure, we evaluate the total squared difference between the two chips. The shift at the global minimum of the correlation measure is taken as the horizontal motion at the spe- 


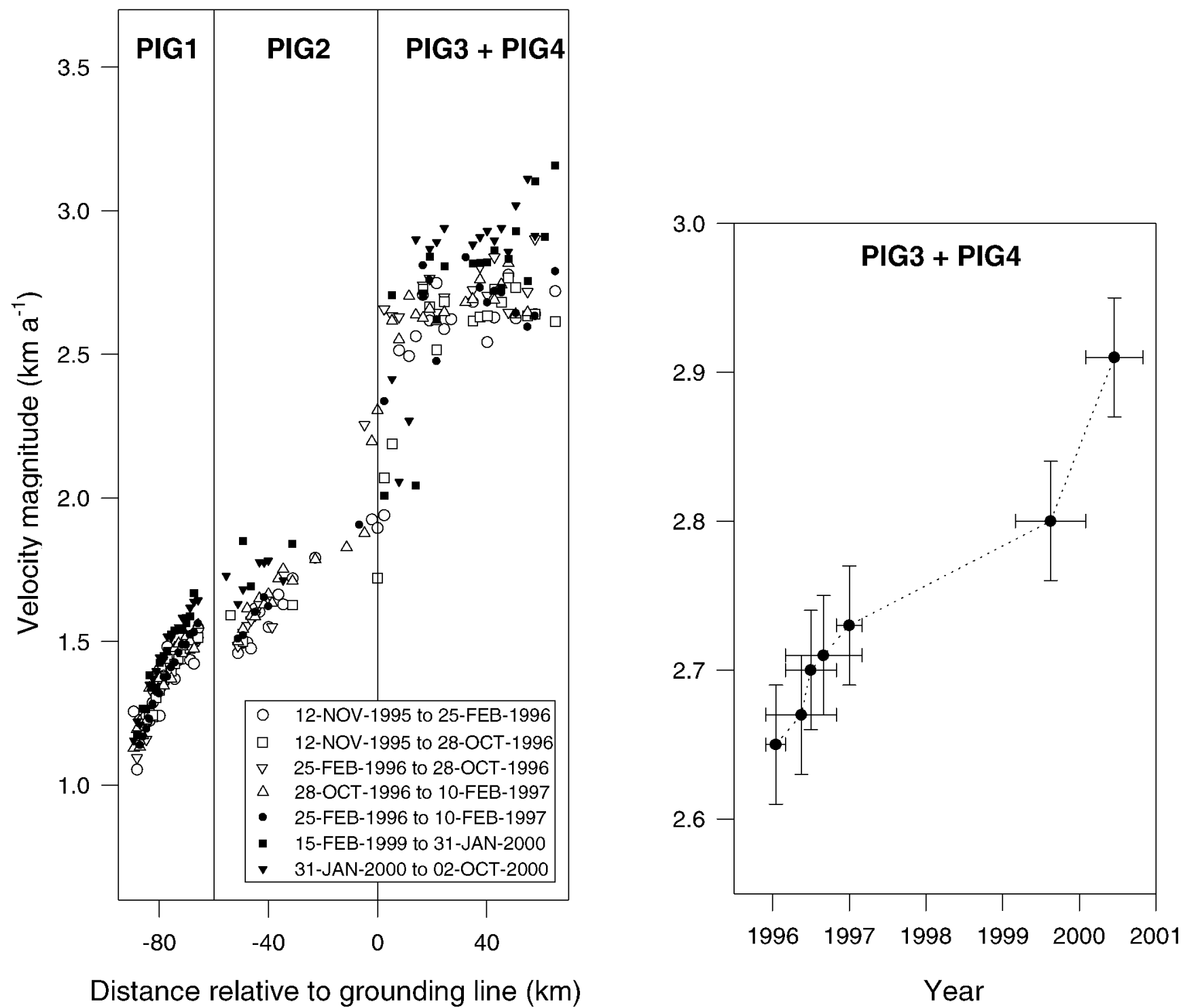

Fig. 2. Velocity magnitude along longitudinal feature-tracking profiles; labels refer to Figure 1. Left: spatio-temporal distribution of velocity magnitude. Right: velocity magnitude as a function of time averaged over profiles PIG3 + PIG4 (on floating part of $P I G)$, respectively.

cified location. We iteratively reduce $d$ from $50 \mathrm{~m}$ to $12.5 \mathrm{~m}$ and $6.25 \mathrm{~m}$ starting with the solution of the previous coarser search step; $D$ is reduced accordingly. The ratio (contrast) of the global minimum with respect to the next largest local minimum is stored as a quality flag. The shortest time interval used for feature tracking in this study is 35 days. For this interval the maximum accuracy of the velocity measurement is about $70 \mathrm{~m} \mathrm{a}^{-1}$; for longer intervals it is proportionally better. In regions without visible surface features the accuracy of the method is severely limited by low contrast of the correlation measure. An exception is short time intervals because image speckle is still partially coherent and is tracked by the method even when no macroscopic surface features are present (e.g. Gray and others, 1998).

In contrast to interferometric velocity measurements, the feature-tracking method represents a longer time interval (months vs days) and gives absolute velocities without requiring reference points of known velocity. Furthermore, no corrections due to tidal motion or topography are necessary. Disadvantages of the feature-tracking method are the lower spatial resolution ( $1 \mathrm{~km}$ vs $50 \mathrm{~m}$ for interferometric SAR) as well as the presence of high random scatter in the results due to lack of surface features or feature confusion.
Our experience is that this random scatter can reduce the accuracy of individual data points to about $200 \mathrm{~m} \mathrm{a}^{-1}$, which, particularly for longer time intervals, is considerably less than the before-mentioned maximum accuracy of the method. This can occur for particular regions of an image pair with a large time interval, where ice motion has led to changes in the orientation and appearance of the surface features, or for an entire image pair if the backscatter amplitude has changed significantly from one image to the next. The latter condition is a rare case for our study area; all of the scenes compiled in Table 1 have extremely similar backscatter, which is visibly dominated by the spatial distribution of surface roughness. The random scatter of the velocity measurements makes the creation of meaningful two-dimensional velocity maps difficult, requiring considerable algorithmic effort for outlier removal, interpolation and smoothing. A more robust alternative is the evaluation of a velocity profile along a given flowline for repeat datasets. In critical regions with low image contrast, additional velocity points can be picked interactively within a swath of the width of the search chip ( $1.5 \mathrm{~km}$ in our case) centered around the flowline. After removing obvious outliers via the beforementioned quality flag, and averaging over profiles com- 



b

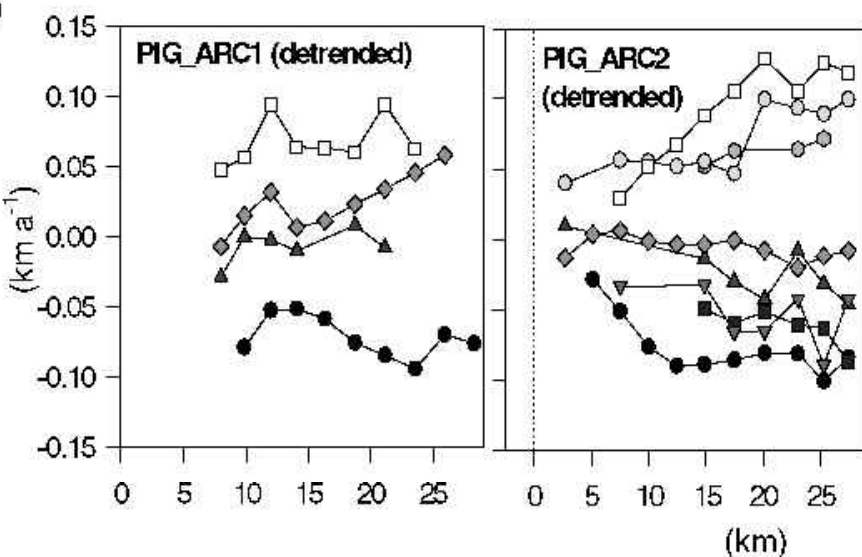

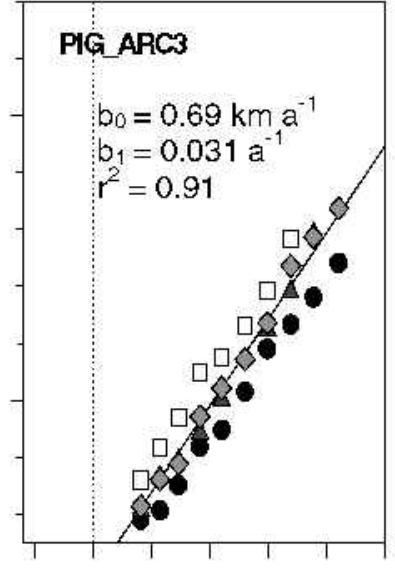

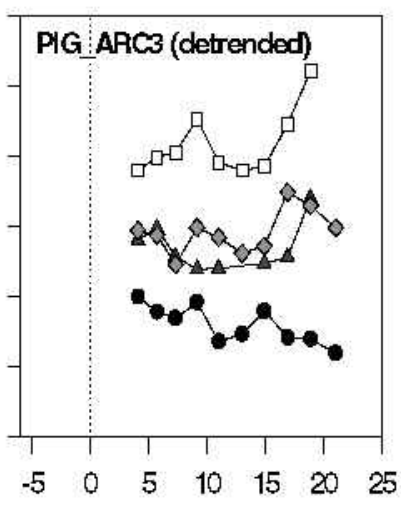

$\rightarrow 09.02 .92$ to $04.12 .92,300 \mathrm{~d}$ $\rightarrow 04.12 .92$ to $15.03 .94,465 \mathrm{~d}$ $\triangle 15.03 .94$ to $12.11 .95,607 \mathrm{~d}$ $\rightarrow-15.03 .94$ to $25.02 .96,712 \mathrm{~d}$ $-0-25.02 .96$ to $10.02 .97,350 \mathrm{~d}$ $\rightarrow-10.02 .97$ to $15.02 .99,735 \mathrm{~d}$ $-0-15.02 .99$ to $31.01 .00,350 \mathrm{~d}$ $\rightarrow-31.01 .00$ to $02.10 .00,245 \mathrm{~d}$

Fig. 3. Spatial and temporal velocity characteristics in the arcuate crevasse zone: (a) velocity magnitude; (b) velocity magnitude minus a linear spatial trend (black solid line in (a)).The $x$ axis refers to path distance from the start of the profile; the location of the crevasse onset averaged over the observation period is at the left border of the graphs.

prising on the order of 100 points, maximum random errors are reduced to less than $25 \mathrm{~m} \mathrm{a}^{-1}$, which we assume as a conservative error bar for our velocity time series.

\section{Mapping the up-glacier limit of the arcuate crevasse zone}

The up-glacier boundary of the zone of arcuate crevasses on PIG at a given image date is traced by the uppermost crevasse visible in the corresponding image. Because new crevasses form at the boundary over time, hereby replacing the previous uppermost crevasse, the boundary of the arcuate crevasse zone is a "feature" that is not passively advected with glacier flow. The boundary was digitized directly in individual GECs, with digitization errors being random and smaller than $100 \mathrm{~m}$. When calculating a time series of the mean position of crevasse onset from $>30$ digitized points, the corresponding error is consequently $<25 \mathrm{~m}$.

\section{Mapping of grounding-line location}

Grounding-line positions are evaluated from the representation of variable vertical tidal motion in quadruple interferograms of PIG (presented before in Rignot, 1998). We additionally consider theoretical complications if the tidal differences between these scenes are small compared to the tidal dynamics (Rabus and Lang, 2002). Misplacement errors including the uncertainty of ephemeral migration of the grounding line with tide level are expected to be smaller than $400 \mathrm{~m}$ for PIG. This error is probably dominated by the sensitivity of the grounding line to tide-level variations, the former being a spatially non-random bias for a given quadruple interferogram. Consequently, no significant reduction of the error is achieved when we use a longer segment of the grounding line to determine a time series of the mean grounding-line position. For simplicity, we assume $400 \mathrm{~m}$ to be a (conservative) error estimate for our time series of grounding-line positions.

\section{RESULTS}

\section{Ghanges of surface velocity}

Velocity magnitude measured with the feature-tracking method along profiles PIG1,2,3,4 is shown in Figure 2. Temporal coverage is November 1995-October 2000. According to these measurements, PIG undergoes temporal velocity variations on the order of $10-15 \%$ of the mean velocity, with velocity differences diminishing up-glacier. The mean velocity has increased monotonically throughout the observation period (Fig. 2b). Noticeable velocity differences reach $>80 \mathrm{~km}$ above the grounding line and about $50 \mathrm{~km}$ past the up-glacier limit of the weakly grounded ice plain discovered by Corr and others (2001).

Compared to the case of the velocity variations found forTG (Rabus and others, 2003), the decision between external and internal forcing for PIG is less obvious. Here, the key question is whether the source of the temporal velocity variations is at the (i) down-glacier or (ii) up-glacier end of the region affected by the velocity variations. In the first case, the velocity variations are caused by the (external) 
a

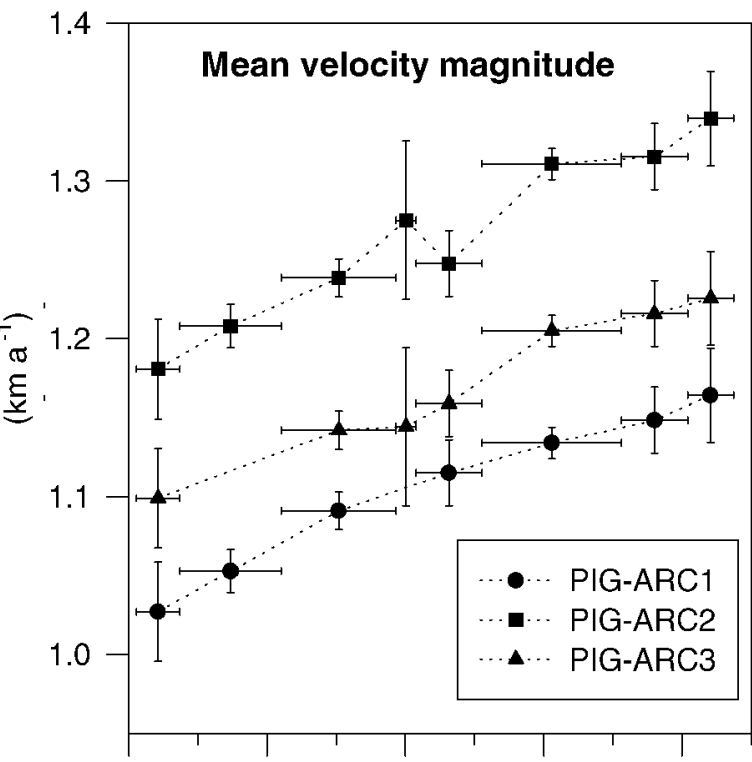

b

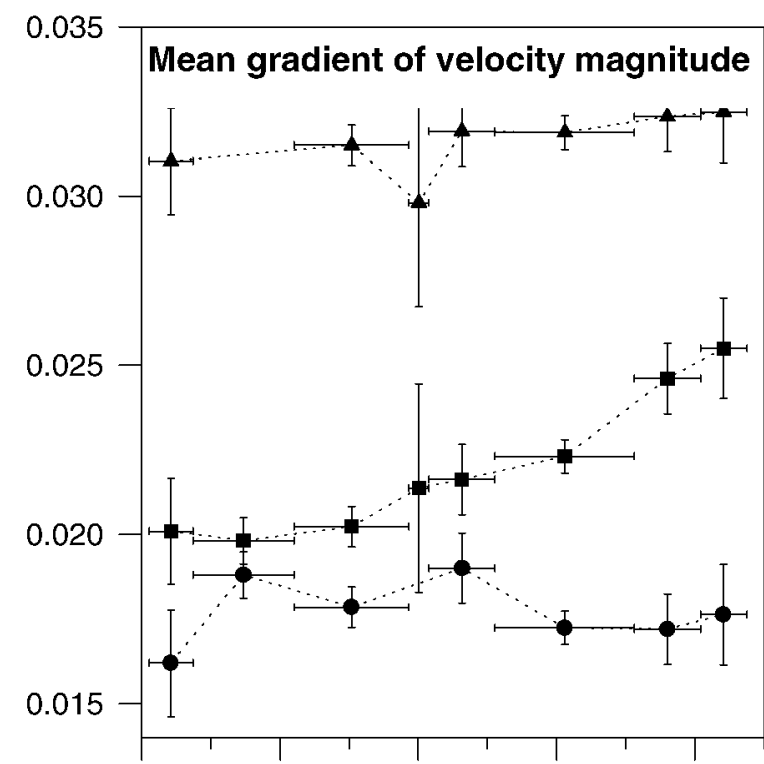

c

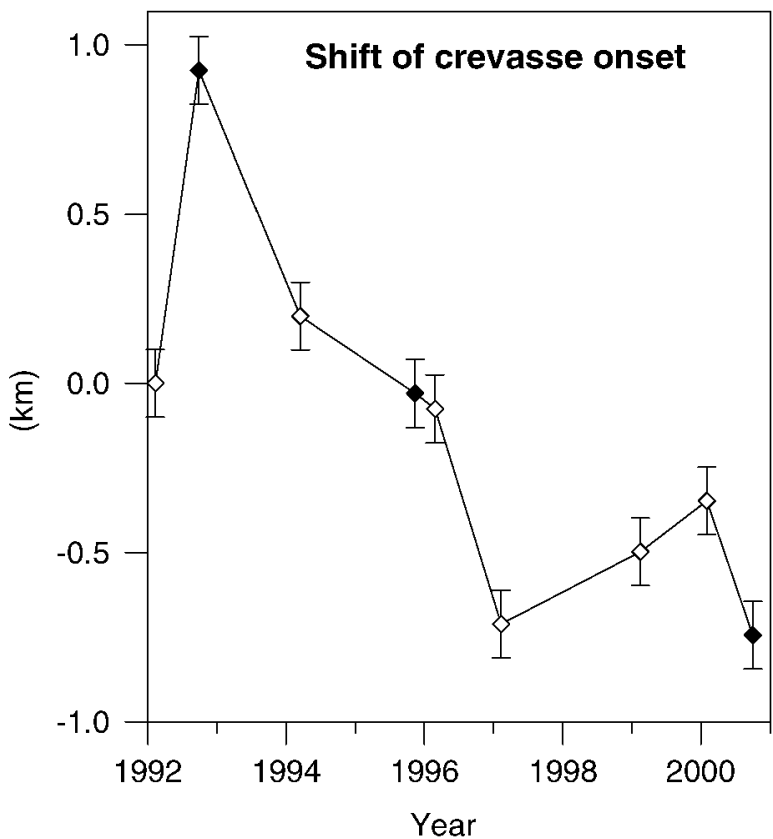

Fig. 4. Temporal velocity changes along profiles PIG_ARC1,2,3 and crevasse-onset migration. (a) Velocity magnitude at $15 \mathrm{~km}$ from average crevasse onset vs time; (b) gradient of velocity magnitude vs time; (c) average crevasse-onset location vs time. dynamics of the floating part of the glacier that is dominated by ocean and sea-ice conditions, while in the second case they are caused by the (internal) dynamics of the grounded parts of the glacier. We are looking for constraints that allow one of the two possibilities to be ruled out.

The upper limit of the observed velocity changes suspected from Figure 2 lies in a region of arcuate crevasses that is visible in Figure 1. For a series of seasonal and interannual image pairs in the period 1992-2000, we calculate feature-tracking velocities along three detailed profiles, PIG_ARC1,2,3, following approximate flowlines through the center and sides of the crevassed section of the glacier (see blow-up in Fig. 1). We are particularly interested in the spatial trend of the velocity profiles when they approach the (uncrevassed) region above the uppermost crevasse. Because PIG_ARC3 unfortunately crosses the frame boundary for several image pairs, velocity measurements are not available closer than $10 \mathrm{~km}$ from the crevasse onset. PIG_ARCl starts at the crevasse onset, but, due to the intense crevassing in this part of the glacier, valid measurements with the feature-tracking method are not obtained $<8 \mathrm{~km}$ down-glacier of the crevasse onset. For the central profile PIG_ARC2, valid measurements are available $5 \mathrm{~km}$ down-glacier of the crevasse onset, and therefore this profile has the greatest potential for up-glacier extrapolation of the spatial trend of velocity change. No suitable surface features were found above the crevasse onset that would allow a reliable up-glacier extension of the feature-tracking velocity measurements.

Figure 3 shows velocity magnitude along the three profiles obtained for the different feature-tracking pairs. For PIG_ARC2 the detrended results immediately show that the velocity change decreases significantly when approaching the crevasse onset. The up-glacier decrease of the velocity variations along PIG_ARCl and PIG_ARC3 at the glacier sides is considerably weaker than for PIG_ARC2 close to the center line. Looking at Figure 3 it is evident that quantitative extrapolation of the velocity change to the crevasse onset will not be reliable, even for PIG_ARC2. As the spatial trend of velocity change appears non-linear, any extrapolation would be dominated by the data points closest to crevasse onset. However, the accuracy of individual feature-tracking data points can be considerably less than the $25 \mathrm{ma}^{-1}$ accuracy that we estimated for an average over several points. As a result, the extrapolated velocity change over the 8 year observation period at the crevasse onset of PIG_ARC2 could be anywhere in the range $0-125 \mathrm{~m} \mathrm{a}^{-1}$. (The corresponding range of velocity change per year is $0-16 \mathrm{~m} \mathrm{a}^{-1}$.)

In Figure $4 a$ and $b$ we show time series of mean velocity and velocity gradient obtained from linear least-squares fitting along the three profiles. The least-squares fit was not carried out on datasets with less than four data points along the profile. Figure $4 \mathrm{a}$ shows that mean velocity displays a near-linear increase over time. The total increase is about $0.15 \mathrm{~km} \mathrm{a}^{-1}$ for each of the profiles. In contrast, the evolution of the velocity gradients in Figure $4 \mathrm{~b}$ is significantly different between the profiles. As expected, the gradient of PIG_ARC2 shows a significant temporal increase consistent with the up-glacier reduction of the velocity variation that is visible in Figure 3. The gradient of PIG_ARC3 also shows a monotonic increase, but the magnitude is much smaller than that of PIG_ARC2. The gradient of PIG_ARCl does not show a net increase or decrease over time.

The latter findings suggest that at the glacier sides the transition from near-uniform to decreasing velocity vari- 
Table 3. Velocity changes per year $\Delta v$ in the arcuate crevasse zone and on the ice shelf

Period $\Delta t$

\section{$\Delta v$}

Ice shelf Arcuate crevasse Arcuate crevasse (km80) zone $(\mathrm{km} 30)$ zone $(\mathrm{kmo})$

days $\mathrm{ma}^{-1} \quad \mathrm{ma}^{-1} \quad \mathrm{ma}^{-1}$

Interferometric analysis (Rignot and others, 2002)

$\begin{array}{lllll}15 \text { Feb. } 1992-11 \text { Nov. } 1995 & 1365 & 56.2 & 28.0 & 17.4 \\ 11 \text { Nov. } 1995-20 \text { Nov. } 1999 & 1470 & 62.1 & 33.5 & 24.8 \\ 15 \text { Feb. } 1992-20 \text { Nov. } 1999 & 2835 & 59.3 & 30.9 & 21.2\end{array}$

Feature-tracking analysis (thisstudy)

$\begin{array}{lccc}\text { 8 July 1992 - 18 Aug. 1996 } & 1502 & - & 24.4 \pm 7 \\ \text { 18 Aug. 1996 - 1 June 2000 } & 1383 & 58.8 \pm 9 & 31.0 \pm 7 \\ \text { 3 Jan. 1996 - 19 Dec. 1996 } & 351 & 83.3 \pm 11 & - \\ \text { 8 July. 1992 - 1 June 2000 } & 2885 & - & 27.6 \pm 5\end{array}$

Notes: Distance is counted from the up-glacier end of the arcuate crevasse zone $(\mathrm{km} 0)$. For the feature-tracking analysis, dates refer to the center of corresponding feature-tracking time intervals.

ations must occur up-glacier of the first valid feature-tracking measurements (and closer to the crevasse onset). If we assume that the velocity increase goes to zero for all profiles at a similar distance up-glacier of the crevasse onset, this indirectly suggests a higher temporal increase of longitudinal extension at the glacier sides. This is compatible with crevasses at the center being considerably less frequent and more

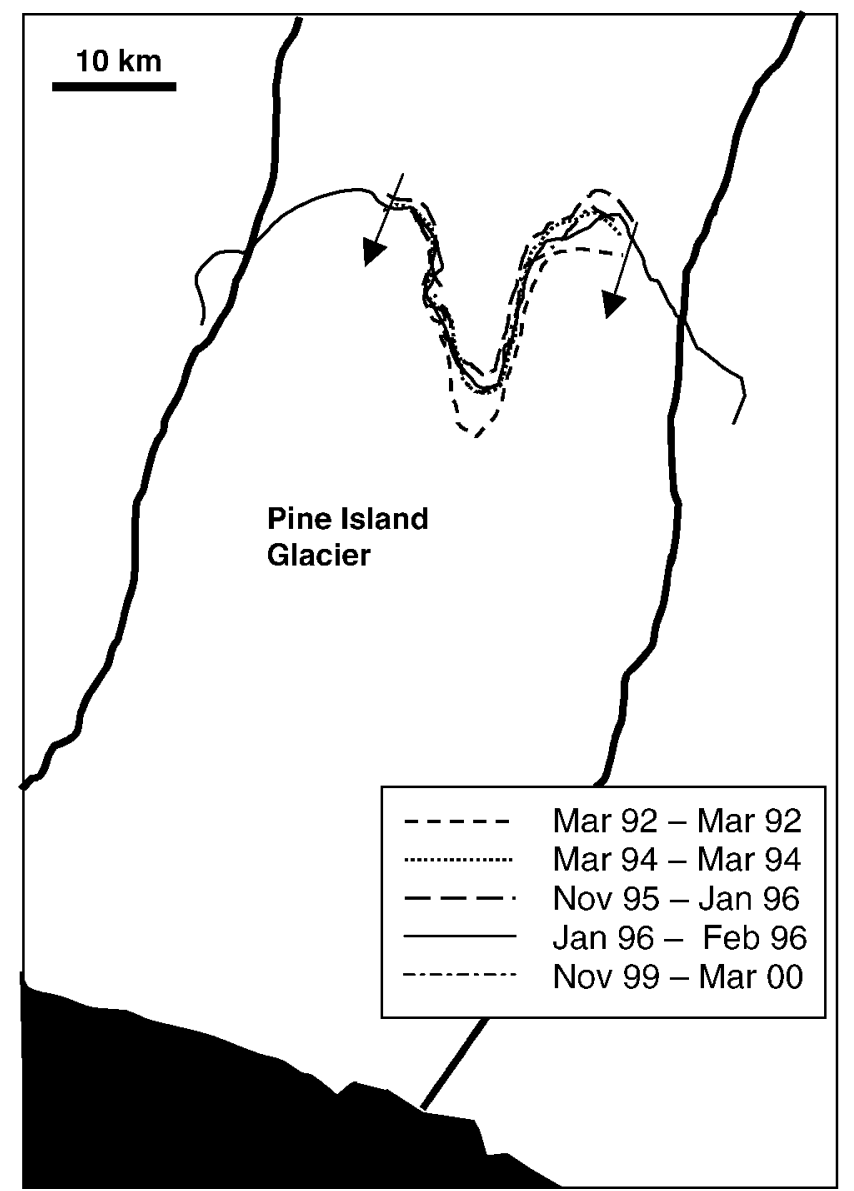

diffuse with respect to the sides (Fig. 1, blow-up). The highest density of crevasses occurs at the east side of the glacier, where PIG_ARCl is located.

\section{Comparison with interferometrically measured velocity change}

Table 3 compares our feature-tracking results with corresponding results from the recent interferometric study by Rignot and others (2002). The center-line profile used by Rignot and others parallels PIG3+4 and PIG_ARC2 within $15 \mathrm{~km}$ distance on the floating part of PIG and in the arcuate crevasse zone, respectively. For our study, velocity change $\Delta v$ in Table 3 is taken from Figures $2 \mathrm{~b}$ and $4 \mathrm{a}$. To make $\Delta v$ values comparable between the studies, we have converted them to velocity change per year in all cases. Within expected error bounds, there is good agreement between the studies. Obtaining similar results with the long-term temporal averaging of the feature-tracking method demonstrates that the interferometric results (representing mere 13 day temporal averages) are not significantly biased by ephemeral velocity changes in this case.

We also compare rates of surface lowering for defined sections of PIG. Following Rignot and others (2002), we calculate surface lowering rate according to

$$
\frac{\Delta h}{\Delta t}=\frac{\Delta v_{1}-\Delta v_{1}}{l_{1}-l_{2}} \frac{H_{1}+H_{2}}{2}-\frac{\Delta v_{1}+\Delta v_{1}}{2} \frac{H_{1}-H_{2}}{l_{1}-l_{2}} .
$$

Here, $H$ denotes ice thickness; corresponding values are taken from Lythe and Vaughan, (2001). The first and second terms in

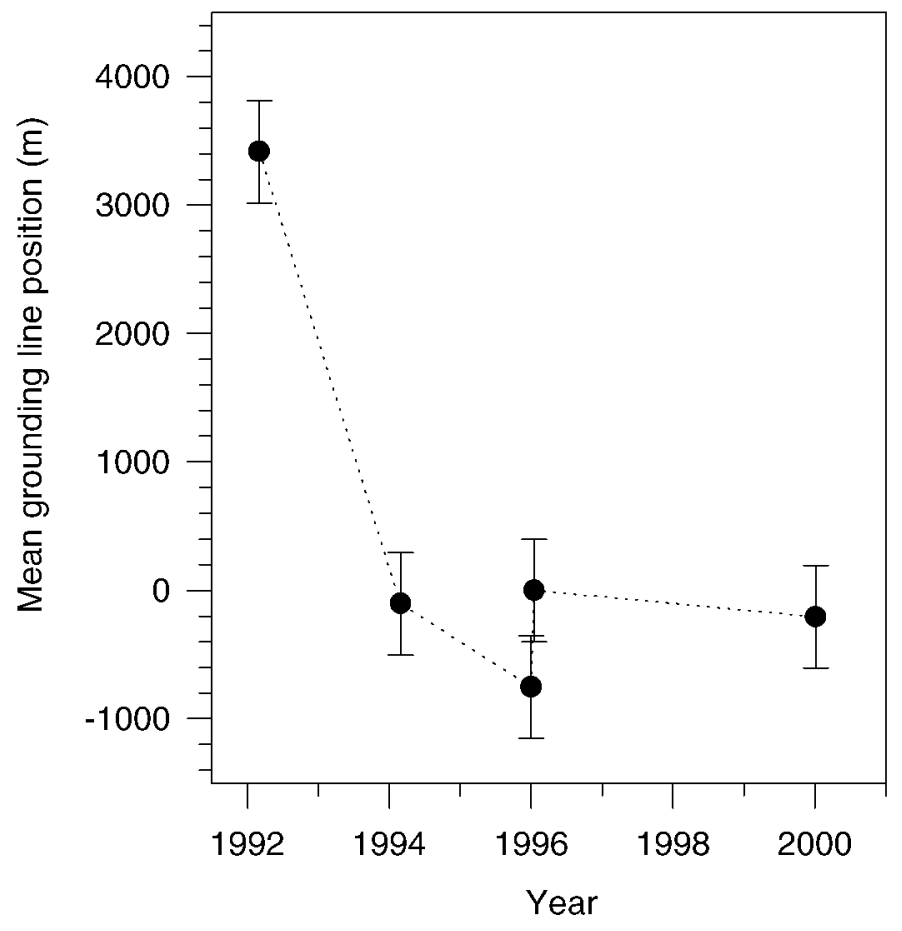

Fig. 5. Fluctuations of grounding-line position of PIG derived from differential interferometric measurements. Left: sketch maps showing reference grounding-line position (solid line) plus grounding-line position at other times along a common sub-segment. Right: mean grounding-line position with respect to the reference along the chosen sub-segment. 
Equation (2) denote thickness change due to vertical strain and advection changes, respectively. As individual values $\Delta v_{1 / 2}$ at $l_{1}=30 \mathrm{~km}$ and $l_{2}=80 \mathrm{~km}$ closely agree between the studies, surface lowering rates will also be similar; for the period 1996-2000 we obtain $\Delta h / \Delta t=-0.17$ and $-0.18 \mathrm{~m}$ $\mathrm{a}^{-1}$ for interferometry and feature tracking, respectively. This differs considerably from values of $-1.1 \mathrm{~m} \mathrm{a}^{-1}$ obtained by Shepherd and others (2001) for this segment of PIG. The shorter segment between 50 and $70 \mathrm{~km}$ chosen by Rignot and others (2002) produces $\Delta h / \Delta t=-0.94 \mathrm{ma}^{-1}$, in closer agreement with Shepherd and others' corresponding value of $-1.5 \mathrm{~m} \mathrm{a}^{-1}$. Close agreement with Shepherd and others' measurements is not necessarily expected, as their values may include a background of ongoing thickness change unrelated to the recent velocity change. Equation (2) only describes the thickness change relative to this background.

We also calculate $\Delta h / \Delta t$ along the center line of the arcuate crevasse zone (profile PIG_ARC2) using $\Delta v$ from Table 3 (numbers refer to the period 1992-2000 in this case). For the stretch between $l_{1}=0 \mathrm{~km}$ (crevasse onset) and $l_{2}=30 \mathrm{~km}$, ice thickness is approximately constant at $H_{1}=H_{2}=$ $1900 \mathrm{~m}$, which renders thickness change by advection negligible here. To bracket $\Delta h / \Delta t$ for the feature tracking, we substitute the estimated error limits 0 and $16 \mathrm{~m} \mathrm{a}^{-1}$ of $\Delta v_{1}$ into Equation (2). Respectively, we obtain $\Delta h / \Delta t=-1.7$ and $-0.7 \mathrm{ma}^{-1}$. Alternatively, we can calculate surface lowering using the linear spatial velocity gradient taken from Figure 4 . For the period $1992-2000$, this produces $\Delta h / \Delta t=(0.020-$ $0.025) \times 1900 / 8 \mathrm{~m} \mathrm{a}^{-1}=-1.2 \mathrm{~m} \mathrm{a}^{-1}$, which as expected falls in between values calculated for the error range of $\Delta v_{1}$. Using the corresponding numbers of Rignot and others (2002) from Table 3, we obtain $\Delta h / \Delta t=-0.6 \mathrm{~m} \mathrm{a}^{-1}$. Finally, Shepherd and others (2001) report surface lowering of $-0.5 \mathrm{~m} \mathrm{a}^{-1}$ for this section of PIG. These results suggest that the velocity variations of PIG likely cannot go to zero at the up-glacier boundary of the arcuate crevasse zone, as this would produce unrealistically large rates of surface lowering in the arcuate crevasse zone. This implication is discussed later on.

\section{Ghanges of crevasse-onset location}

For a segment in the vicinity of PIG_ARCl (Fig 1, blow-up) we digitized the crevasse onset for all images involved in the feature tracking. The area enclosed by the uppermost crevasse at subsequent image dates was calculated, and divided by the length of the uppermost crevasse (mean of the two image dates). The resulting time series of spatially averaged crevasse-onset location is shown in Figure 4c. The succession of filled and open symbols representing (austral) spring and fall dates, respectively, shows that there are no systematic seasonal oscillations of crevasse-onset location. Nevertheless, short-term fluctuations like the one from austral fall 1992 to austral spring 1992 can occur. The apparent long-term trend of crevasse migration, however, suggests that new crevasses are spawned up-glacier at an average rate not compensated by glacier motion. This causes a net inland extension of the crevassed zone.

It is interesting to calculate how this extension compares quantitatively with the observed surface velocity increase. Total migration of the crevasse onset from 1992 to 2000 is on the order of $0.8 \mathrm{~km}$ corresponding to $100 \mathrm{~m} \mathrm{a}^{-1}$. Extra displacement during the 8 year observation period due to the velocity increase was $0.5 \times(8$ years $) \times\left(0.15 \mathrm{~km} \mathrm{a}^{-1}\right)=0.6 \mathrm{~km}$, corresponding to $75 \mathrm{~m} \mathrm{a}^{-1}$. If PIG were undergoing a true surge, the opening of just a few deep crevasses within the $100 \mathrm{~m}$ increment marking the advance of the up-glacier surge front would explain the observed extra displacement. Velocity change would be zero up-glacier of the crevasse onset and constant throughout the arcuate crevasse zone. In the discussion section we will see, however, that the scenario of a true surge conflicts with several other observations and constraints.

\section{Changes of grounding-line position}

Figure 5 shows changes in grounding-line position since 1992 across the central part of PIG. It is apparent that the initial $3.5 \mathrm{~km}$ retreat during the period 1992-94 that was first seen by Rignot (1998) did not continue linearly but was followed by stagnation of the mean grounding-line position during the period 1994-2000. Even the large retreat of the grounding line during the earlier period could result from a mere ephemeral reduction in ice thickness because the lowermost grounded part of PIG is a nearisostatic ice plain (Corr and others, 2001).

\section{DISGUSSION}

The surface velocity of the floating shelf and grounded trunk of PIG has increased near-linearly during the period 19922000. During the same period, other substantial changes have occurred at both the upper and lower ends of the region of the observed temporal velocity change. The floating part has shown (a) retreat of the grounding line (Rignot, 1998; Fig. 5) and (b) recent retreat of the ice front due to the calving of a large iceberg (R. A. Bindschadler, http://nsidc.org/ iceshelves/pine_island). Further, (c) the onset of pronounced arcuate crevassing $80 \mathrm{~km}$ inland of the grounding line has been migrating up-glacier in near unison with the velocity increase in the crevassed zone (Fig. 3).

\section{Interpretation of recent velocity change}

We are faced with the question whether the velocity variations of PIG observed during the last decade are actively caused (i) by an internal flow instability, or alternatively (ii) by the external dynamics of the floating glacier parts. The first possibility involves variations of the back pressure that is caused by shear against the slow-moving marginal ice shelves surrounding the floating part of PIG as well as basal shear of the ice plain immediately above the grounding line. Calving of the ice front or retreat of the grounding line will cause negative back-pressure variations that propagate up-glacier, leading to increased crevassing far inland. The second possibility leads to positive longitudinal stress that then would have caused an enhanced down-glacier velocity increase. This enhanced velocity increase may then cause destabilization of the floating glacier parts, leading to dynamic thinning and grounding-line retreat as well as enhanced calving.

There are several arguments that persuade us that an internal flow instability is causing the recent velocity variations of PIG. The active region of this internal forcing must be in or up-glacier of the arcuate crevasse zone.

First, the time series of velocity increase and crevasseonset migration both show significant linear trends, while this is clearly not the case for the time series of groundingline retreat (Fig. 5) or that of ice-front calving (the ice front was remarkably stable up to the great calving event of 2001). Secondly, if grounding-line retreat had caused the velocity increase, one would expect the back-pressure anomaly 
caused by the $1.3 \mathrm{~km} \mathrm{1992-94}$ grounding-line retreat propagating up-glacier to be reflected in the later velocity data. This is, however, not the case. Thirdly, strong spatial gradients of velocity change caused by a flow instability originating in the arcuate crevasse region are expected to become increasingly subdued while propagating down-glacier. This is consistent with observed small gradients of velocity change near the grounding line, as well as indirectly with the lack of more dramatic grounding-line retreat.

That the entire floating part of PIG (including the ice plain) is currently passive is independently confirmed by Rignot and others (2002) who find near-constant velocity change in this region (their fig. 2). In contrast, active external forcing (e.g. through recent back-stress variations by calving at the ice front or by unstable friction at the shear margins) should cause significant spatial gradients of velocity change on the floating part of PIG. Velocity increase between 1996 and 2000 at the lower boundary of the arcuate crevasse region $\left(0.15 \mathrm{~km} \mathrm{a}^{-1}\right)$ is two times smaller than at the upper boundary of the ice plain $\left(0.3 \mathrm{~km} \mathrm{a}^{-1}\right)$, but the relative velocity increase is remarkably similar at about $9 \%$. Because the floating part appears passive, this again suggests forcing by longitudinal stress changes up-glacier of the region considered, i.e. in or above the arcuate crevasse zone.

The up-glacier boundary of the suspected internal flow instability is not well constrained by the feature-tracking data. The boundary must be several kilometers above the onset of arcuate crevasses. This is because zero velocity change at the crevasse has been shown to produce unrealistically high rates of surface lowering. Further, zero velocity change at the glacier center (compatible with the data from profile PIG_ARC2) would imply a velocity discontinuity at the glacier sides because variations appear uniform for profiles PIG_ARCl and PIG_ARC3 as close as $10 \mathrm{~km}$ downglacier of the crevasse onset. Such a discontinuity would require the formation of surge-type crevasses reaching deep into the interior of the glacier. Such crevasses would need to be water-filled to form and stay open, a condition which is incompatible with the cold climatic conditions in this region of PIG (Vaughan and others, 2001). Finally, no velocity discontinuity is visible in the one differential interferogram of Rignot and others (2002) that has sufficient-quality coverage of the arcuate crevasse zone. Judged from this interferogram, which represents a comparison of 1 day velocity averages in 1996 and 2000, the region of velocity change seems to extend about $25 \mathrm{~km}$ up-glacier of the crevasse onset. Velocity change per year along the crevasse onset is on the order of $15 \mathrm{ma}^{-1}$ across the central part of the main glacier trunk.

\section{Origin of the flow instability}

While a flow instability associated with the arcuate crevasse region likely causes the current down-glacier velocity variations of PIG, we can only speculate on what caused the flow instability in the first place. This is because the strong temporal trend of the variations implies that the velocity of PIG probably increased many years before observations began in 1992. Both internal and external forcings could have been the original trigger. Mass-balance fluctuations in the upper PIG drainage, thought by Wingham and others (1998) to explain their observations of surface elevation change, are an example of possible internal forcing, while adjustment due to past changes of ice-shelf configuration in Pine Island Bay could be a potential external reason.

\section{CONGLUSION}

Using a simple feature-tracking technique on ERS amplitude images, we have shown that PIG shows interannual surface velocity variations of $10-15 \%$ reaching from the floating part to $>80 \mathrm{~km}$ above the grounding line. At the accuracy level of the method $\left(\sim 25 \mathrm{~m} \mathrm{a}^{-1}\right)$, there is no indication of seasonal velocity variations. Our results corroborate a recent interferometric analysis by Rignot and others (2002) which compares velocities with very short temporal averaging periods compared to those of the feature tracking (days vs months). The close agreement between the studies indirectly demonstrates the absence of shorter-term velocity fluctuations for PIG that would otherwise have contaminated the interferometric analysis.

On PIG, we observe a continuous velocity increase over time that reaches $\sim 80 \mathrm{~km}$ above the grounding line into a zone of arcuate crevasses. During 1992-2000, velocity change was around $+0.2 \mathrm{ma}^{-1}$ in the lower arcuate crevasse zone. The velocity change approaches zero in the uppermost section of the arcuate crevasse zone. The accuracy of our method is not sufficient to rule out potential velocity variations $<25 \mathrm{~m} \mathrm{a}^{-1}$ up-glacier of the arcuate crevasse zone. The most likely explanation for the velocity variations of PIG is a continuing flow instability in or up-glacier of the arcuate crevasse region, shown also by simultaneous up-glacier migration of the crevasse limit by about $100 \mathrm{~m} \mathrm{a}^{-1}$.

What originally caused the region of internal flow instability on PIG cannot be determined with available data. If there was an initial external forcing event, it must predate the beginning of the measurements in 1992 by at least several years. Our results therefore emphasize the need for future long-term studies of individual ice streams. High-resolution velocity time series are an important prerequisite for understanding the individual dynamics of West Antarctic ice streams and interpreting their observed changes correctly.

\section{ACKNOWLEDGEMENTS}

We are grateful for continued support by the German Remote Sensing Center (DFD-DLR). Particular thanks go to $\mathrm{K}$. Reiniger and his team for processing the ERS SAR data and to M. Eineder and his team for providing support on the interferometric processing system GENESIS. Some of the material presented in this study was prepared by $\mathrm{M}$. Mueller as part of his master thesis; we want to thank him very much for his enthusiasm and the good collaboration.

\section{REFERENGES}

Bamber, J. L. and R. A. Bindschadler. 1997. An improved elevation dataset for climate and ice-sheet modelling: validation with satellite imagery. Ann. Glaciol., 25, 439-444.

Bentley, C. R. 1998. Rapid sea-level rise from a West Antarctic ice-sheet collapse: a short-term perspective. f. Glaciol., 44(146), 157-163.

Corr, H. F. J., C. S. M. Doake, A. Jenkins and D. G. Vaughan. 2001. Investigations of an "ice-plain" in the mouth of Pine Island Glacier, Antarctica. f. Glaciol., 47(156), 51-57.

Fastook, J. 1984. West Antarctica, the sea-level controlled marine instability: past and future. In Hansen, J. E. and T. Takahashi, eds. Climate processes and climate sensitivity. Washington, DC, American Geophysical Union, 275-287. (Geophysical Monograph 29, Maurice Ewing Series 5.)

Gray, A. L., K. E. Mattar and P. W. Vachon. 1998. InSAR results from the RADARSAT Antarctic mapping mission data: estimation of data using a simple registration procedure. In Stein, T., ed. IGARSS'98. 18th Inter national Geoscience and Remote Sensing Symposium, 6-10 July 1998, Seattle, Washington. Proceedings. Piscataway, NJ, Institute of Electrical and Elec- 
tronics Engineers, 1638-1640.

Hughes, T. 1973. Is the West Antarctic ice sheet disintegrating? f. Geophys. Res., 78(33), 7884-7910.

Lythe, M. B., D. G. Vaughan and BEDMAP Consortium. 2001. BEDMAP: a new ice thickness and subglacial topographic model of Antarctica. 7 . Geophys. Res., 106(B6), 11,335-11,351.

Rabus, B. T. and O. Lang. 2002. On the representation of ice-shelf grounding zones in SAR interferograms. F. Glaciol., 48(162), 345-356.

Rabus, B. T., O. Lang and U. Adolphus. 2003. Interannual velocity variations and recent calving of Thwaites Glacier Tongue, West Antarctica. Ann. Glaciol., 36 (see paper in this volume).

Rignot, E.J. 1998. Fast recession of a West Antarctic glacier. Science, 281 (5376), 549-551.

Rignot, E., D. G. Vaughan, M. Schmeltz, T. Dupont and D. MacAyeal. 2002. Acceleration of Pine Island and Thwaites Glaciers, West Antarctica. Ann. Glaciol., 34, 189-194.

Rosanova, C. E., B. K. Lucchitta and J. G. Ferrigno. 1998. Velocities of Thwaites Glacier and smaller glaciers along the Marie Byrd Land coast, West Antarctica. Ann. Glaciol., 27, 47-53.

Scambos, T. A., M. J. Dutkiewicz, J. C. Wilson and R. A. Bindschadler. 1992. Application of image cross-correlation to the measurement of glacier velocity using satellite image data. Remote Sensing Environ., 42(3), 177-186. Schreier, G., ed. 1993. SAR geocoding data and systems. Germany, Wichmann. Shepherd, A., D. J. Wingham, J. A. D. Mansley and H. F.J. Corr. 2001. Inland thinning of Pine Island Glacier, West Antarctica. Science, 291(5505), 862-864.

Stenoien, M. D. and C. R. Bentley. 2000. Pine Island Glacier, Antarctica: a study of the catchment using interferometric synthetic aperture radar measurements and radar altimetry. F. Geophys. Res., 105(B9), 21,761-21,779.

Vaughan, D. G. and 9 others. 2001. A review of Pine Island Glacier basin, West Antarctica: hypotheses of instability vs. observations of change. In Alley, R. B. and R. A. Bindschadler, eds. The West Antarctic ice sheet: behavior and environment. Washington, DC, American Geophysical Union, 237-256. (Antarctic Research Series 77.)

Wingham, D. J., A. L. Ridout, R. Scharroo, R. J. Arthern and C. K. Shum. 1998. Antarctic elevation change 1992 to 1996. Science, 282(5388), 456-458. 